\title{
Behavioral field analysis in two strains of rats in a conditioned defensive burying paradigm
}

\author{
AKIRA TSUDA, YOSHISHIGE IDA, and MASATOSHI TANAKA \\ Kurume University School of Medicine, Kurume, Japan
}

\begin{abstract}
Two strains of rats (albino Wistar and hooded PVG/c) were exposed to a conditioned defensive burying paradigm that consisted of placing rats in a test chamber with bedding material on the floor, shocking them with a shock prod, and recording the time each rat spent in burying responses toward the prod. Various behaviors other than burying (freezing, grooming/paw licking) were observed by a time-sampling procedure during the control, conditioning, and extinction sessions, each of which was 15 min in duration. Wistar rats generally showed behavioral inhibition, as evidenced by less burying, lower exploratory and ambulatory behavior, and higher freezing behavior. PVG/c rats spent significantly more time engaged in burying and accumulated more bedding material in the conditioning session than did the Wistar rats. No significant differences between the two strains of rats were observed during the extinction session in terms of these measurements. The results indicate that Wistar rats have a greater tendency to freeze when coping with the noxious stimulus in a conditioned defensive burying paradigm, whereas the dominant coping style for PVG/c rats is defensive burying.
\end{abstract}

Exposure to a conditioned defensive burying paradigm (Pinel \& Treit, 1978), wherein animals are placed in a test chamber with bedding material on the floor and shocked by a shock prod, has been shown to initiate a robust burying sequence; that is, shocked animals typically display spraying of the bedding toward the prod with thrusting movements of the forepaws and rapid shoveling with the snout. This burying behavior of the shocked animals is thought to be controlled by a conditioned association between the shock and the prod, because it is influenced by the degree of spatial and temporal contiguity between shock and contact with the prod (Arnaut \& Shettleworth, 1981).

Since Pinel and Treit (1978) originally demonstrated this paradigm, there has been a substantial body of evidence regarding mechanisms involved in the conditioned defensive burying paradigm (for a review see Pinel \& Wilkie, 1983). Precipitating factors that have been examined include characteristics of the aversive stimulus (Poling, Cleary, \& Monaghan, 1981), type of burying material (Pinel \& Treit, 1979), size of chamber (Davis, Moore, Cowen, Thurston, \& Maggio, 1982), and testing condition (Modaresi, 1982). Predisposing factors have proven to be important in determining whether defensive burying occurs. Some studies have dealt with intraspecific (Harder \& Maggio, 1983) or cross-specific variations

This research was supported by a Grant-in-Aid for Encouragement of Young Scientists (60710097) to A. Tsuda from the Ministry of Education, Science and Culture of Japan. We would like to thank Gary B. Glavin of the Department of Pharmacology and Therapeutics, University of Manitoba, Winnipeg, Canada, for his kind reviewing of an earlier version of this manuscript. Requests for reprints should be addressed to Akira Tsuda, Department of Pharmacology, Kurume University School of Medicine, Kurume 830, Japan.
(Davis, Whiteside, Heck, \& Dickson, 1981) and age or sex differences (Treit, Terlecki, \& Pinel, 1980) as they affect defensive burying. Although defensive burying seems to be one type of species-specific defense reaction, few studies have reported defensive burying behavior for any strain of rats other than hooded rats, which Pinel and Treit (1978) originally used as subjects. Moreover, there is little agreement among reports of strain differences in this behavior. Tarte and Oberdieck (1982) found that Long-Evans hooded rats spent significantly more time burying than did Wistar albino rats, although McKim and Lett (1979) and Treit et al. (1980) had reported no differences between these strains of rats.

Along with the problem of strain differences, most studies have not systematically measured any behaviors other than burying, and only very limited data exist concerning the relationship between defensive burying and other behaviors in a conditioned defensive burying situation (Moser \& Tait, 1983; Peacock \& Wong, 1982). Since the mean time engaged in burying typically represents only a fraction of the total observation time of the standard 15min test, as Peacock and Wong (1982) noted, it is not clear what other behaviors occur in this situation.

For the sake of a better understanding of defensive behavior in rodents, it is worthwhile to observe not only defensive burying but also other defensive behaviors occurring in the test situation, as well as general behaviors. The purpose of the present experiment was to see whether any strain differences in burying behavior existed between PVG/c hooded rats and Wistar albino rats, and whether such differences were due to changes in the coping response repertoires of these strains induced by aversive stimulation in a defensive burying paradigm, using a behavioral field analysis. 


\section{METHOD}

\section{Subjects}

The subjects consisted of 8 male Wistar albino and 8 male PVG/c hooded rats that were purchased from a local animal supplier (Seiwa Animal Laboratory, Chikuzyo-gun, Fukuoka). These rats weighed $190-250 \mathrm{~g}$ and were 8 weeks old when they were received from the vendor and they were acclimated to the laboratory for 10 days prior to being used as experimental subjects. The rats were housed in groups in an air-conditioned room $\left(24^{\circ} \pm 1^{\circ} \mathrm{C}\right.$, relative humidity $50 \% \pm 10 \%$ ) and kept on a $12-\mathrm{h}$ (light on 0700 to 1900) lightdark cycle. Food and water were provided ad lib.

\section{Apparatus}

The testing apparatus consisted of an acrylic plastic box $(30.5 \mathrm{~cm}$ wide $\times 45 \mathrm{~cm}$ long $\times 44 \mathrm{~cm}$ high) with $5 \mathrm{~cm}$ of white flaked bedding material (Charles River Japan, Atsugi, Kanagawa) on the floor. A removable carbonate prod $(19.5 \mathrm{~cm}$ long, $1.2 \mathrm{~cm}$ in diameter), wrapped with two uninsulated wires, extended $6.5 \mathrm{~cm}$ into the testing chamber through the center of the wall of the chamber $2 \mathrm{~cm}$ above the top of the bedding material. Electric shock generated by a shock generator-scrambler (SGS-001, Muromachi Kikai Co., Tokyo) was delivered to the two wires of the shock prod. Illumination was provided by a $20-\mathrm{W}$ white light bulb mounted $20 \mathrm{~cm}$ above the center of the chamber ceiling.

\section{Procedure}

Habituation to the testing apparatus without the shock prod was done with squads of 4 rats for 30 -min periods on 3 consecutive days. On Day 4, the rats were placed individually in the chamber for 15 min with the shock prod in its usual place. This control session served as a burying baseline period; thus, no aversive stimulus was given during this time. Twenty-four hours later, on Day 5, each rat was returned to the chamber. When the rat touched the prod for the first time, a brief shock (4-mA shock intensity), initiated by the experimenter and terminated by the withdrawal of the subject, was presented. The rat then remained confined to the chamber without additional aversive stimulation for a 15 -min postshock burying conditioning session. On Day 6 (extinction session), each rat was placed in the chamber for a $15-\mathrm{min}$ period. No aversive shock was presented even when the rat touched the shock prod during this session.

For the control, conditioning, and extinction sessions, buryingrelated behaviors were observed by two independent observers, using standard timers and event counters. Latency and frequency of occurrences and amount of time spent engaging in a particular behavior were recorded. The number of approach-avoidance responses, defined as a rat's being oriented toward the shock prod in an extended position and then suddenly withdrawing from the prod, was also noted. During each session, other general behaviors were recorded by the same observers, using a time-sampling procedure. Every $30 \mathrm{sec}$, the behavior in which the animal was currently engaged was classified into one of seven mutually exclusive categories: (1) burying - moving toward the shock prod and spraying or pushing the bedding material toward the prod with rapid movements of the snout or forepaws; (2) freezing - the rat's body weight was supported nol by its belly but by its hindlimbs, which were contracted, with forelimbs extended; (3) lying-the rat's hindlimbs, forelimbs, and belly touched the floor and supported its body weight; (4) rearing-raising the body on the hindlimbs in a vertical position; (5) sniffing - sniffing activity directed at the floor, almost always accompanied by lowering of the head; (6) ambulation-any diffuse locomotor activity, ranging from a single step to moving about in the chamber; (7) grooming/paw licking-cleaning, rubbing, licking, or scratching of the body, facial area, or forelimbs. At the end of each session, the height of piles of bedding material within $10 \mathrm{~cm}$ of the prod was measured. These behavioral measures have high interobserver reliability. For example, the correlation coefficient between the durations of burying behavior recorded by the two observers was $r(46)=.93, p<.01$.

\section{RESULTS}

\section{Burying-Related Behaviors}

For the topography of shock-prod contacts at the time of shock, there were no remarkable differences between Wistar-strain albino rats and PVG/c-strain hooded rats. The two strains of rats touched the shock prod with forepaws in the same manner.

Table 1 summarizes various measures of defensive burying-related behaviors as a function of strain and sessions. For duration of burying, a two-way analysis of variance (ANOVA) revealed significant main effects of strain $[F(1,42)=18.9, p<.01]$ and session $[F(2,42)$ $=16.8, p<.01 \mathrm{~J}$, as well as a significant interaction between these factors $[F(2,42)=11.9, p<.01]$. Tukey's HSD post hoc comparisons $(\alpha<.05)$ indicated that the hooded rats engaged in more defensive burying during the conditioning and extinction sessions than in the control session, although the duration of burying in the Wistar rats was increased as a function of sessions. The PVG/c rats spent significantly more time engaged in defensive burying during the conditioning session than did the Wistar rats.

Table 1

Summary of Conditioned Defensive Burying Behaviors as a Function of Strain and Sessions

\begin{tabular}{|c|c|c|c|c|c|c|c|c|c|c|}
\hline \multirow[b]{2}{*}{ Session } & \multicolumn{2}{|c|}{$\begin{array}{c}\text { Duration of } \\
\text { Burying (sec) }\end{array}$} & \multicolumn{2}{|c|}{$\begin{array}{c}\text { No. of } \\
\text { Burying Responses } \\
\end{array}$} & \multicolumn{2}{|c|}{$\begin{array}{c}\text { Latency of } \\
\text { Burying (sec) }\end{array}$} & \multicolumn{2}{|c|}{$\begin{array}{c}\text { No. of Approach- } \\
\text { Avoidance Responses }\end{array}$} & \multicolumn{2}{|c|}{$\begin{array}{l}\text { Height of } \\
\text { Pile }(\mathrm{cm})\end{array}$} \\
\hline & $M$ & $S E M$ & $M$ & $S E M$ & $M$ & $S E M$ & $M$ & $S E M$ & $M$ & $S E M$ \\
\hline \multicolumn{11}{|c|}{ Wistar-Strain Albino Rats } \\
\hline Control & 14.4 & 7.3 & 5.6 & 2.4 & & & & & 5.2 & 0.1 \\
\hline Conditioning & 39.5 & 13.7 & 14.9 & $3.4^{*}$ & 179.8 & 108.3 & 1.1 & 0.5 & 7.0 & 0.9 \\
\hline Extinction & 54.5 & 17.9* & 17.9 & $5.9^{*}$ & 148.4 & 46.6 & 5.0 & $2.4 \dagger$ & 8.0 & 1.1 \\
\hline \multicolumn{11}{|c|}{ PVG/c-Strain Hooded Rats } \\
\hline Control & 23.3 & 7.0 & 9.3 & 2.7 & & & & & 5.9 & 0.4 \\
\hline Conditioning & 199.1 & $26.7 *$,‡ & 19.3 & $4.4^{*}$ & 73.1 & 40.1 & 5.8 & $1.2 \ddagger$ & 9.8 & $0.8^{*}, \ddagger$ \\
\hline Extinction & 71.1 & $22.2 *, \dagger$ & 17.3 & $3.5^{*}$ & 79.5 & 18.0 & 9.4 & $1.1+, \ddagger$ & 8.1 & $0.8 *, \dagger$ \\
\hline
\end{tabular}

*versus respective control session $(\alpha<.05)$. †versus respective conditioning session $(\alpha<.05)$. †versus Wistar rats $(\alpha<.05)$. 
ANOVAs of the number of burying responses revealed that the occurrence of burying was increased as a function of experience with shock $[F(2,42)=4.3, p<.05]$. Both PVG/c and Wistar rats displayed more defensive burying during the conditioning and extinction sessions than in the control session. The two strains of rats did not differ significantly from each other in terms of the frequency of burying during each session. Although the latency of burying was not statistically significant due to large variability, burying latency tended to be shorter in the PVG/c rats than in the Wistar rats during the conditioning and extinction sessions $(p<.10)$.

There were significant main effects of session $[F(1,28)$ $=6.4, p<.05]$ and strain $[F(1,28)=9.2, p<.05]$ in terms of the number of approach-avoidance responses. Rats of both strains showed more approach-avoidance responding directed at the shock prod during the extinction session than in the control session. These increases were significantly greater in the PVG/c rats than in the Wistar rats. There were reliable differences in the height of the bedding piles for strain $[F(1,42)=3.7, p<.05]$ and session $[F(2,42)=8.4, p<.05]$. The mean height for the PVG/c rats was greater during the conditioning and extinction sessions than during the control session. In the conditioning session, the PVG/c rats accumulated bedding material significantly more than did the Wistar rats.

\section{General Behaviors}

Figure 1 shows the frequency of various general behaviors observed during each session for the PVG/c and Wistar rats. These behaviors were analyzed by separate two-way ANOVAs. For burying, there were reliable main effects for strain $[F(1,42)=15.4, p<.01]$ and session $[F(2,42)=11.4, p<.01]$, as well as a significant interaction between these factors $[F(2,42)=3.9, p<.05]$. Although both Wistar and PVG/c rats showed significantly more burying during the conditioning and extinction sessions than in the control session, the PVG/c rats displayed reliably more burying than did the Wistar rats in the conditioning session.

For freezing behavior, both main effects, that is, strain $[F(1,42)=7.7, p<.01]$ and session $[F(2,42)=7.4$, $p<.01]$, were significant, but the interaction of these factors was not significant. Although both strains of rats displayed significantly more freezing during the conditioning session than in the control session, the Wistar rats froze reliably more than did the PVG/c rats in the conditioning session. In the extinction session, freezing for the Wistar rats declined to control levels. Wistar rats displayed significantly more grooming/paw licking behavior than did PVG/c rats across sessions $[F(1,42)=25.7$, $p<.01]$. The Wistar rats displayed grooming/paw licking more reliably in the extinction session than in the control and conditioning sessions $[F(2,42)=4.5, p<.05]$.

There were reliable main effects for strain $[F(1,42)=$ $27.2, p<.05]$ and session $[F(2,42)=5.3, p<.05]$ in terms of rearing behavior. Rearing for the Wistar rats remained at a relatively low level. The strain effect was significant for ambulation $[F(1,42)=5.5, p<.05]$, with PVG/c rats showing more ambulation than the Wistar rats in the control and extinction sessions. Sniffing decreased significantly as a function of sessions for both $\mathrm{PVG} / \mathrm{c}$ and Wistar rats $[F(2,42)=8.2, p<.01]$; however, the strain
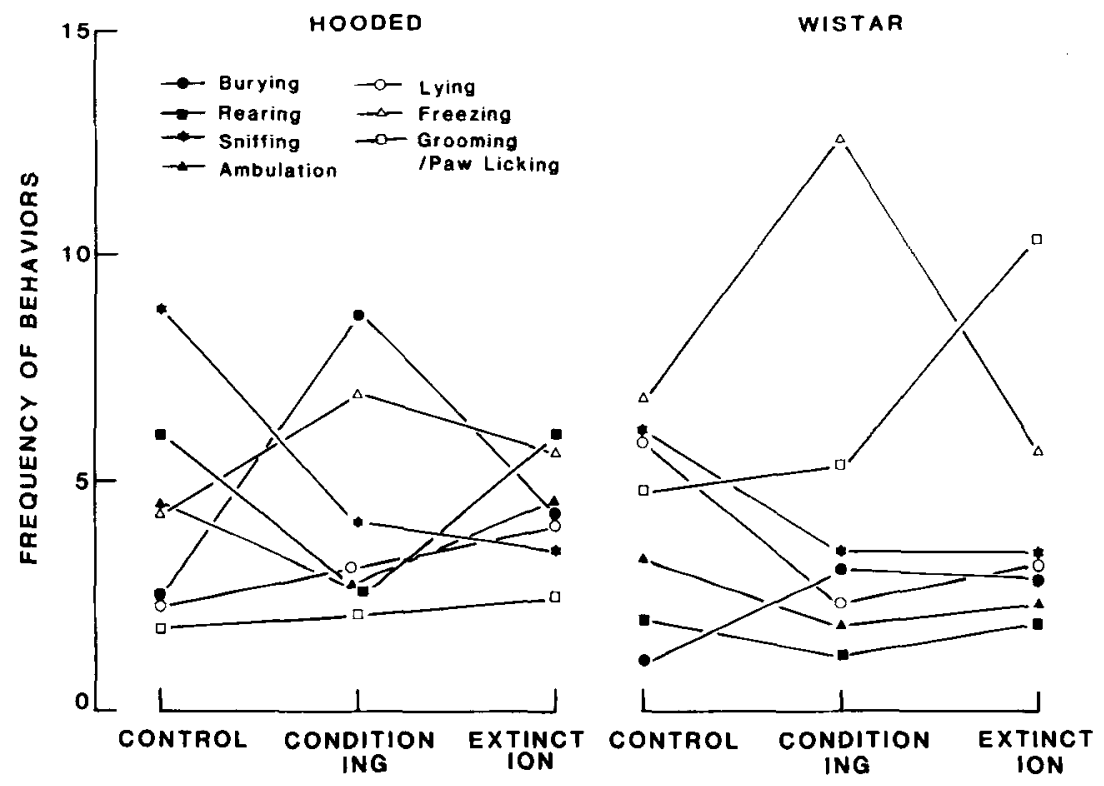

Figure 1. Mean frequency of each behavior observed for the Wistar-strain albino rats and PVG/c-strain hooded rats at the control, conditioning, and extinction sessions. 
effect was not significant. For lying, neither the strain nor the session main effect was significant; the interaction of strain and session was also not significant.

\section{DISCUSSION}

The results of this experiment illustrate that there are significant differences between Wistar-strain albino rats and PVG/c-strain hooded rats in terms of defensive burying-related responses and general behaviors following shock. The data suggest that the defensive reactions of rats exposed to aversive stimuli under the conditioned defensive burying paradigm are dependent on withinspecies differences. It is apparent from this experiment that the PVG/c hooded rats spent more total time burying, that their burying per response was longer in duration, and that they accumulated more bedding material than did the Wistar albino rats in the conditioning session, although no significant differences were observed during the extinction session. The PVG/c rats, unlike the Wistar rats, also showed a tendency to bury the shock prod spontaneously in the control session.

Previous investigations examining strain differences between hooded and albino rats in shock-induced burying have proven inconclusive. Some investigators have found that the duration of burying behavior of albino rats was not significantly different from that of hooded rats (McKim \& Lett, 1979; Treit et al., 1980). Others have reported that Long-Evans-strain hooded rats engaged in more burying than Wistar-strain albino rats (Tarte \& Oberdieck, 1982). The results of the present experiment are consistent with the latter report, and suggest that the emergence of defensive burying might be interactively determined by response repertoire changes produced by aversive stimulation (Moser \& Tait, 1983; Peacock \& Wong, 1982).

In view of the generality of conditioned defensive burying responses, defensive burying is really regarded as part of the defensive repertoire of the rat (Pinel \& Treit, 1978; Treit et al., 1980). Nevertheless, the present findings of defensive burying differences between albino rats and hooded rats should more appropriately be viewed as a demonstration of different defensive response networks in these strains (Moser \& Tait, 1983). One purpose of the present study was to assess multiple defensive responses in a conditioned defensive burying paradigm, by using a behavioral field analysis. Obviously, defensive behaviors, including defensive burying, are different depending upon strain. The present data illustrate that the occurrence of burying appears to interact with the emergence of competing defensive responses other than burying.

In the present experiment, Wistar rats clearly had a greater tendency to freeze during the conditioning session. Their postshock defensive response repertoires consisted of freezing at the start of the session, followed later by burying, as evidenced by a relatively delayed latency to bury and then increases in burying during the extinction session. These animals rapidly acquired freezing as a form of passive avoidance response, instead of burying. A review of the literature (Bolles \& Fanselow, 1980) suggests that rats, especially albino rats such as the Wistar strain, tend to become immobile in situations in which they receive shock. Therefore, on the basis of the magnitude of these responses and their order of emergence, the dominant defensive response repertoires for the Wistar rats were freezing and later burying. However, during the extinction session the Wistar rats showed significantly less freezing; they buried more and displayed more approach-avoidance responses directed toward the shock prod, and also spent more time engaged in grooming/paw licking responses, such as recuperative behaviors (Bolles \& Fanselow, 1980), than they did in the conditioning session. These altered defensive response hierarchies seem to reflect the differentiation of animals' fear under a defensive burying paradigm. If we assume that the probability of burying is greater at moderate levels of fear, then Wistar rats might be considered as a more "emotional" or "fearful" strain than PVG/c rats.

For the PVG/c hooded rats, on the other hand, burying emerged as a major defensive response in the conditioning session. These observations replicated previous studies in demonstrating that shock elicited more burying in hooded rats than they had shown during preshock (baseline) sessions (Goldberg, Ghezzi, \& Cheney, 1983; Pinel \& Treit, 1979). The present data reveal that burying consistently occurred for longer time periods after initial freezing. Concurrently, large percentage decreases in exploratory behavior were observed in terms of rearing, sniffing, and ambulation. In the extinction session, burying for the PVG/c rats declined significantly, although it was still higher than the control levels. It is clear that although burying is readily conditioned to the shock prod, this response is also readily reduced to moderate levels in the extinction session. Pinel, Puttaswamaiah, and Wilkie (1985) recently found that the conditioned defensive burying behavior of hooded rats could be extinguished in a few days by exposing the rats to the conditioning box and shock prod for 15 min each day. It seems plausible that in the present study the PVG/c hooded rats' fear was decreased in the extinction session, as indicated by a suppression of defensive burying and by the appearance of lying/passive responding, as long as they escaped from the source of a threatening object (i.e., shock prod).

In summary, although conditioned defensive burying was observed in both Wistar and PVG/c rats, the behavior emerged to different degrees in the two strains. The finding that Wistar rats reliably displayed defensive burying in the extinction session but not in the conditioning session, whereas the PVG/c rats consistently showed defensive burying in both sessions, could be attributed to strain- 
specific characteristics in shock-induced defensive response repertoires. The behavioral field analysis used in this experiment clearly suggests that when Wistar rats are shocked, they are more likely to use a passive avoidance strategy (e.g., freezing) than an active avoidance strategy (e.g., burying). On the other hand, PVG/c rats' coping style in a threatening situation seems to be an active one. This study also confirms that conditioned defensive burying occurs in the same situation that produces other defensive behaviors (Treit, LoLordo, \& Armstrong, 1986). The occurrence of burying behavior appears to be a function of innately determined defensive response networks as well as the levels of fear evoked in a conditioned defensive burying paradigm.

\section{REFERENCES}

Arnaut, L., Shettleworth, S. J. (1981). The role of spatial and temporal contiguity in defensive burying in rats. Animal Learning \& Behavior, 9, 275-280.

Bolles, R. C., Fanselow, M. S. (1980). A perceptual-defensiverecuperative model of fear and pain. Behavioral \& Brain Sciences, 3, 291-323. (Includes commentary)

Davis, S. F., Moore, S. A., Cowen, C. L., Thurston, D. K., a MAGGio, J. C. (1982). Defensive burying in the Mongolian gerbil (Meriones unguicularus) as a function of size and shape of the test chamber. Animal Leaming \& Behavior, 10, 516-520.

Davis, S. F., Whiteside, D. A., Heck, D. G., Dickson, V. A. (1981). Defensive burying: A cross-species replication and extension. Bulletin of the Psychonomic Society, 17, 45-47.

Goldererg, S. G., Ghezzi, P. M., Cheney, C. D. (1983). Rat defensive behavior: Burying an operandum associated with reinforcement. Psychological Record, 33, 191-199.

HARDER, D. B., \& MAGGio, J. C. (1983). Defensive burying by mice: Intraspecific genetic variation and retention. Animal Learning \& Behavior, 11, 465-473.

McKim, W. A., \& LETT, B. T. (1979). Spontaneous and shock-induced burying in two strains of rats. Behavioral \& Neural Biology, 26, 76-80.
Modaresi, H. A. (1982). Defensive behavior of the rat in a shock-prod situation: Effects of the subject's location preference. Arimal Leaming \& Behavior, 10, 97-102.

Moser, C. G. . TArr. R. W. (1983). Environmental control of multiple defensive responses in a conditioned burying paradigm. Joumal of Comparative Psychology, 97, 338-352.

Peacock, E. J., Wong, P. T. P. (1982). Defensive burying in the rat: A behavioral field analysis. Animal Leaming \& Behavior, 10. 103-107.

Pinel, J. P. J., Puttaswamaiah, S., Wilkie, D. M. (1985). Extinction of conditionad defensive burying. Behavioural Processes, 10, 101-110.

Pinel, J. P. J., \& Treit, D. (1978). Burying as a defensive response in rats. Joumal of Comparative \& Physiological Psychology. 92. 708-712.

Pinel, J. P. J., Treit, D. (1979). Conditioned defensive burying in rats: Availability of burying materials. Animal Leaming \& Behavior. 7. 392-396.

Pinel, J. P. J., WILkIE, D. M. (1983). Conditioned defensive burying: A biological and cognitive approach to avoidance learning. In R. L. Mellgren (Ed.), Animal cognition and behavior (pp. 285-318). New York: North-Holland.

Poling, A., Cleary, J., \& Monaghan, M. (1981). Burying by rats in response to aversive and nonaversive stimuli. Joumal of the Experimental Analysis of Behavior, 35, 31-44.

TARTE, R. D., OEerDieck, F. (1982). Conditioned defensive bury ing in rats as a function of preexposure and strain. Psychological Record, 32, 101-107

Treit, D., LoLordo, V. M. \& Armstrong, D. E. (1986). The effects of diazepam on "fear" reactions in rats are modulated by environmental constraints on the rat's defensive repertoire. Pharmacol. ogy. Biochemistry \& Behavior, 25, 561-565

Treit, D., Terlecku, L. J., \& Pinel, J. P. J. (1980). Conditioned defensive burying in rodents: Organismic variables. Bulletin of the Psychonomic Society, 16, 451-454.

(Manuscript received November 3, 1987; revision accepted for publication February 2, 1988.) 